\title{
¿Fundamentación de la ética? La vida humana: De Porfirio Miranda a Ignacio Ellacuría
}

\author{
EnriQue Dussel
}

UAM-Iztapalapa, México

RESUMEN: Este ensayo examina los abordajes de Porfirio Miranda e Ignacio Ellacuría sobre la fundamentación de la ética. Desde una perspectiva hegeliana, Miranda niega la posibilidad de fundamentar la ética desde la vida humana, punto en el cual difiere crucialmente con Ellacuría, cuya postura se expresa en el título de uno de sus artículos: "Fundamentación biológica de la ética".
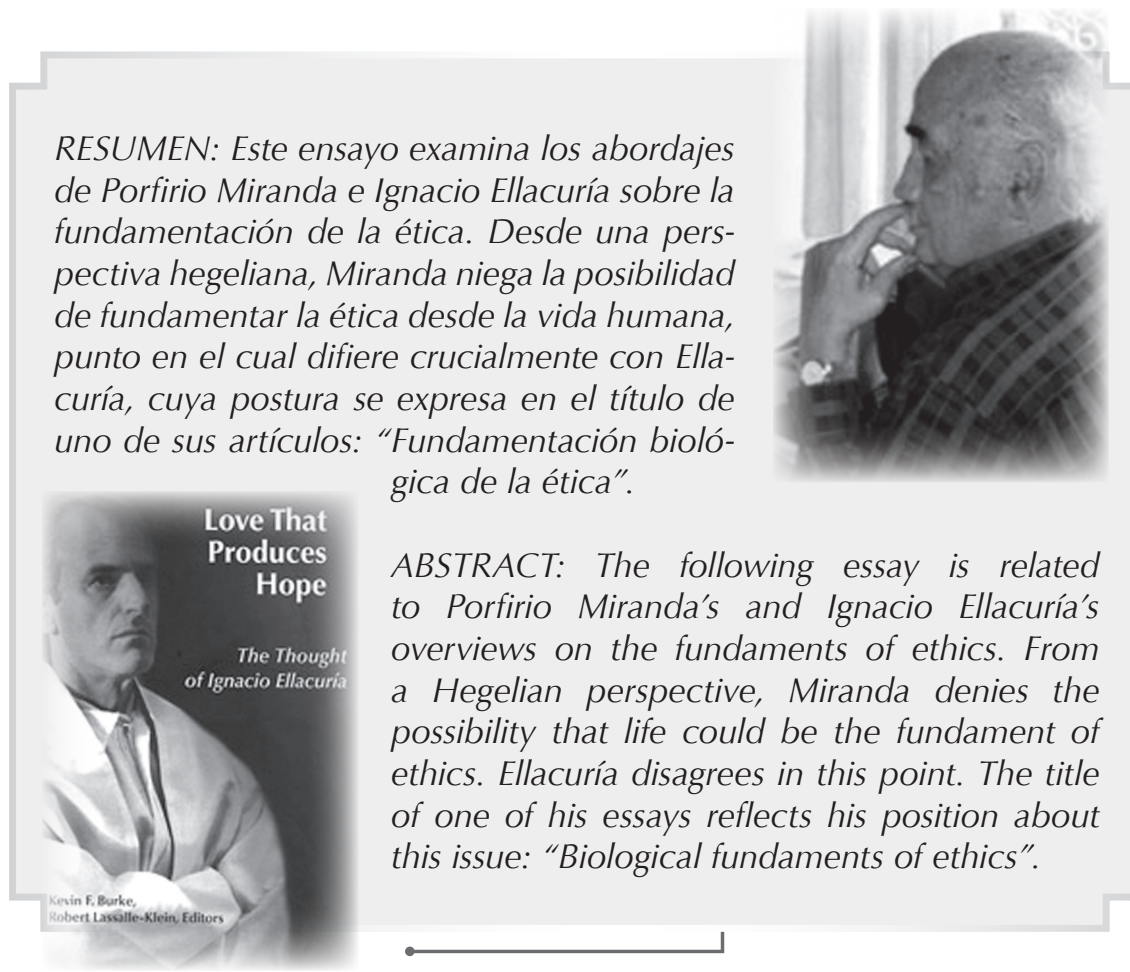

ABSTRACT: The following essay is related to Porfirio Miranda's and Ignacio Ellacuría's overviews on the fundaments of ethics. From a Hegelian perspective, Miranda denies the possibility that life could be the fundament of ethics. Ellacuría disagrees in this point. The title of one of his essays reflects his position about this issue: "Biological fundaments of ethics". 
diálogo que se ha abierto sobre el tema de la vida humana deseo comenzarlo a partir de los trabajos de un discípulo de Porfirio Miranda y mío: Mario Rojas. Sus críticas en parte ya han sido vertidas por otros colegas ${ }^{1}$, pero las suyas tienen novedad. Tomaré el asunto tal como el lo expone para poder aclarar y profundizar el tema de la "fundamentación" en referencia a la "vida".

Nuestra exposición tomará dos ejemplos paradigmáticos. Porfirio Miranda, que combatiendo al positivismo lógica adoptó al final una interpretación propia del pensamiento hegeliano, negando la posibilidad de una fundamentación de la ética desde la vida humana. Por el contrario, Ignacio Ellacuría, partirá del tema de la vida desde su juventud y desarrollará todo su pensamiento a partir de esta clave fundamental, llegando a escribir un artículo sobre la "Fundamentación biológica de la ética" ${ }^{\prime 2}$.
La cuestión parte del haber expresado la necesidad de seguir trabajando el tema de la fundamentación tal como lo hicimos en la Ética de la Liberación, aunque allí sólo lo hicimos indicativamente, por lo que es necesario continuar tratando la cuestión. Esto se debe a que en esa Ética la intención era mostrar el panorama completo del discurso $-y$ la sola fundamentación me hubiera llevado demasiado tiempo y no habría podido exponer lo que me había impuesto-. Por ello vuelvo y volveré sobre el asunto. Cuando se expresa que es necesario una "fundamentación positiva y material"3, se está indicando que hay diferentes modos de "fundamentación", siendo la fundamentación lógica trascendental (de tipo kantiana, apeliana, o hegeliana) una de ellas, pero las hay igualmente como "fundamentación" ontológica o meta-física (en el sentido levinasiano, y aún zubiriano). Pero esto nos lleva ya al primer punto del diálogo.

\section{Dialéctica involutiva hacia el "sujeto" o dialéctica hacia la realidad de "lo real"}

Hace treinta años recordábamos:

"No es lo mismo que se parta del hecho primigenio (factum) para ir hacia algo más-allá (trascendencia) que él, o para ir hacia más-acá (inmanencia trascendental) que él. Esto es fundamental para comprender el sentido de la dialéctica en la historia de la cultura occidental"4. 
Hegel ciertamente involuciona, es un proceso hacia la inmanencia del sujeto. Por ello, nos dirá Porfirio Miranda que "la idea de lo real se origina en la introspección, puesto que las impresiones sensibles no pueden contener ese dato" ${ }^{\prime \prime}$. Es decir, lo "primordialmente real significa espíritu" (Ibid.) ${ }^{6}$. Estamos al nivel de la ontología y de la antropología.
En este caso la autoconciencia, como autonomía del sujeto, define la racionalidad como la nota esencial del ser humano, el momento supremo, por el que puede existir un sujeto, un yo, la conciencia, la autoconciencia, etc.:

"La razón es la instancia que comprende y exige el desarroIlo de la vida humana precisamente hacia lo más humano, más ético, lo cual a mi modo de ver sólo puede significar realización de la razón autónoma, o puesto de otro modo, realización de cada ser humano como sujeto racional autónomo en su constitutiva relación intersubjetiva"

Esta tesis es ampliamente expuesta en su tesis doctoral por Mario Rojas ${ }^{8}$. En el fondo es la postura de la Modernidad, desde Descartes, Kant y Hegel, de la afirmación del sujeto cognitivo (ego cogito) en sus múltiples y cada vez más ontológica auto-fundamentación. Esto podría ser juzgado como un racionalismo radical, en el que desde la fundamenación de un (no varios) principio se deduce toda acción humana, cotidiana, ética, política o estética.

Todo parte del concepto que se tenga de "lo real" y la "realidad".
Si tomamos el camino del realismo crítico de un Xavier Zubiri, la cuestión es radicalmente impostada de otra manera. En primer lugar, no se distingue entre conocimiento de los sentidos (del cuerpo) y conocimiento racional (del alma), sino que más adecuadamente desde un punto de la percepción (recuérdese a Maurice Merleau-Ponty) y de la neurología, hay una "inteligencia sentiente" o un "sentido inteligente". Superamos ya un dualismo innecesario. $Y$ ahora vamos al tema. Se nos dice:

"La aprehensión de lo real es en primer lugar un acto exclusivo de la inteligencia. Los estímulos aprehendidos por la inteligencia no están aprendidos estimúlicamente, sino que están aprehendidos realmente [...] Aprehender algo como real es el acto elemental de la inteligencia [...] La aprehensión de realidad es el acto exclusivo [...], elemental, radical y primario de inteligir, es decir, la aprehensión de realidad es lo que formalmente constituye lo propio del inteligir"9. 
Aquí tenemos una posición diametralmente opuesta a la de Hegel o P. Miranda.

En efecto, el cerebro humano capta lo real para manejarlo a fin de reproducir su vida. Se llama "actualidad" el modo que como lo real es inteligido (neuronalmente) como real; es decir, con realidad. El cerebro animal no tiene la capacidad de superar los estímulos y no puede actualizar la realidad de lo real. La "realidad es la formalidad del de suyo" (Ibid., p.151) de la cosa real. De otra manera:

"Realidad es, ante todo, [...] una formalidad de alteridad de lo aprehendido sentientemente. Y este momento consiste en que lo aprehendido queda en la aprehensión como algo en propio, algo de suyo. Reidad o realidad es formalidad del de suyo. Este de suyo es el momento según el cual lo aprehendido es ya lo que está aprehendido. Este ya expresa la anterioridad formal de lo aprehendido respecto de su estar aprehendido: es el prius"110.

Demos un paso adelante:

"Los animales todos tienen cada uno su constitución propia y, por tanto, su propia forma de realidad [...] El animal tiene una independencia y un control específico sobre el medio fundada en gran medida en el sentir. [...] El animal tiene siempre un primordium, cada vez más rico en la serie zoológica [...] Es un modo de realidad distinto del tener notas en propio; es un nuevo modo de realidad que llamamos vida. Vida no es auto-moción, [...] sino que es un modo de auto-posesión, esto es, ser en realidad y sentirse un autós.[...] El hombre tiene todavía un modo de realidad más hondo. El hombre no es solamente algo que se posee, algo autós, sino que es autós de un modo distinto. [...] Se pertenece a sí mismo como realidad: es persona. Persona es formal y reduplicativa suidad real"11.

¿Qué es en este caso verdad?:

"Verdad es el momento de la actualización de lo real en intelección sentiente en cuanto tal. [...] Este momento de formalidad de suyo es un momento de la cosa anterior (prius) a su propio estar aprehendida. Y en esto consiste su realidad. Pero claro está, este de suyo anterior a la aprehensión está, sin embargo, aprehendido en su propia anterioridad. [...] $Y$ este de suyo, esta realidad, en cuanto presente en la aprehensión es justamente la verdad. Verdad es realidad presente en intelección en cuanto está realmente presente en ella. [...]: ratificación"12. 
Verdad se da sólo en la subjetividad humana, y su criterio es la

J

P. Miranda escribió Hegel tenía razón ${ }^{13}$, donde explica su interpretación de la filosofía hegeliana. Comienza por una crítica al esteticismo ${ }^{14}$, opinando que la estética se funda en "juicios puramente subjetivos" -adoptando una posición próxima a la de Platón ${ }^{15}$; que es inevitable el enjuiciar a la cultura occidental como la superior comparándola especialmente con las culturas amerindias (criticando despiadadamente al "indigenismo"; $;$. Se muestra anti-historicista (p. 12), anti-pluralista (p. 13), anti-culturalista (p. 15), anti-escéptico (p. 15); afirmando que hay solo una filosofía (p. 16); juzgando negativamente al evolucionismo (p.20). En fin, se manifiesta un eurocentrismo decidido (pp. 21-23), atacando el enunciado: "todas las culturas son iguales" en su valor (posición trivial que nadie puede proponer, y que habría que diferenciar de: "todas las culturas tienen valores que en algún aspecto pueden enseñar a las otras soluciones para acrecentar la cualidad de la vida humana". Y, en general, un anti-cientificismo, ya que al negarle a las ciencias naturales o sociales la capacidad de su propia fundamentación pareciera negarle al mismo tiempo toda racionalidad o eficacia. La filosofía sería la ciencia propiamente dicha (p. 28). vida humana. Veamos sin embargo la posición de Hegel al respecto.

\section{La posición hegeliana}

Todo esto se explica en el capítulo II: “¿Por qué el sujeto?", en el que se expone que el conocimiento científico no es empírico, si por empírico se entiende conocimiento sensible. Todo conocimiento científico se basa en "conceptos", en "teorías", y "el significado o el concepto debemos [sólo] buscarlo en el sujeto cognoscente" (p.44). La ciencia no puede definir sus supuestos: la geometría el espacio, la física la materia, etc. Sin definición no hay concepto, y sin concepto, la realidad se desvanece.

En el capítulo III, se nos explica que "el espíritu es pensamiento" (p. 81); "el espíritu es nada fuera de sus pensamientos" (lbid.). Siendo que la materia no se puede definir, no es real. Desde Aristóteles, pasando por Descartes y Hegel, Miranda identifica: $y o=$ concepto $=$ alma $=$ espíritu $=$ conciencia $=$ acto cognitivo = autoconciencia; todos como "actividad" (p. 82). El espíritu es auto-determinación (Selbsbestimmung) (p. 86), libertad (p. 86), intersubjetividad (Sittlichkeit), comunidad histórica (histórico mundial). No es una substancia (pp. 90ss); no son las apetencias (p. 113ss).

La dialéctica (pp. 175ss) es el movimiento de resolución de los momentos abstractos contradictorios 
del entendimiento (Verstand) por retorno al sujeto (ese retorno es propio de la razón: Vernunft).

La vida de la que se habla, como lo veremos en Hegel, es la idea de vida. Así "los animales y las plantas tiene vida en la medida que se asemejan al hombre" (pp. 230ss).

Lo implícito desde el comienzo, porque juega la función de un a priori, es el Estado, anterior al individuo. El Estado es la totalidad de todos los derechos y deberes de los ciudadanos, el contenido final de la historia y la subjetividad. Por ello, "los deberes con el prójimo" constituyen lo universal, en la comunidad y la intersubjetividad (p. 303). Por naturaleza el ser humano no es humano, lo deviene por la sociedad: es un reino espiritual.

Podemos concluir que, como en sus obras restantes (incluyendo las de Porfirio sobre Marx), Miranda más trabaja por registro de conceptos (utilizando el volumen final temático de las obras de Hegel o Marx) que por la lógica de su pensamiento. Puede verse cuando indica, por ejemplo, lo que significa "espíritu", trayendo colación muchos "textos" de esos registros temáticos. La organización conceptual es de Miranda, y aproximadamente la de Hegel o Marx. De todas maneras puede concluirse que en buen hegelianismo "lo que es racional (vernünftig) es lo real (wirklich), y lo que es real es lo racional" (Enzyklop. § 6; Hegel, 1970, 8, p. 47). Pero entiéndase que aquí "racional" y "real" son predicados de un campo propiamente pensado, racional, del concepto. Y, por ello, puede decirse que "lo racional es lo real" en todo el mundo de la cultura, de los productos humanos que tiene por origen al mismo ser humano (el horizonte filosófico, científico, las instituciones sociales, políticas, estéticas), ya que tienen a la racionalidad teórica o práctica como su fuente originaria. Como la estructura de la obra del arquitecto en su realidad lógica (es decir, "estructural") se identifica tanto con el plano diseñado como con la forma real de la obra producida.

El espíritu se trataría de algo así como el conjunto de todos los yo en vigilia, concientes, auto-concientes, libres, en acto cognoscentes intersubjetivamente como humanidad, en el presente de la historia mundial; es decir, como "concepto". Sería como la noosfera de Teilhard de Chardin, aunque éste sabía de la realidad de la biosfera, de la admósfera y del universo cósmico eran distintos, mientras que en Miranda han desaparecidos fagocitadas por el "espíritu", sin materia, más allá de la vida física. Parecería que se hubiera caído en un subjetivismo (acósmico), un racionalismo (anti-epistémico), un psiquismo dualista (de alma sin cuerpo), un formalismo político (donde la política se reduce a sólo deberes y derechos). ¿Es esto un invento de Miranda? ¿No habrá en Hegel mismo suficiente sugerencias para indicar que es una posible interpretación del pensamiento de Hegel? 
En efecto, si releemos algunos textos de Hegel nos da la impresión que la interpretación de Miranda es acertada. En la Lógica mayor, cuando buscamos el tema de la vida lo encontramos en un momento culminante de la Lógica. Pero se trata no de la vida real (diría Marx), sino de "la idea de la vida" (die Idee des Lebens) (Hegel, 1970, 6, p. 469; Mondolfo, 1968, p. 671). En este sentido "la verdad consiste en el conocer (Erkennen)" (Ibid.), en "conocer el concepto" (Erkennen der Begriff). Se trata entonces de "la contemplación lógica de la vida" (P. 470; P. 672). Esta vida no es objeto científico ni es la "vida natural". Es sólo "la vida en cuanto está en vinculación con el espíritu" (p. 471; p. 672). La vida natural es sólo "condición (Bedingung)" -como los objeta Apel y Mario Rojas-; la vida de la que habla Hegel es "la vida del espíritu" (des Geistes), que se contrapone a la "simple vida" (bloßen Leben). La vida natural es la del "individuo viviente"; la vida de la "corporalidad viviente" (lebendigen Körporlichkeit) (p. 472; p. $672) 17$, pero no es "la vida lógica" (logische Leben). La "vida del espíritu es un misterio inconceptualizable" (unbegreifliches Geheimnis) (p. 473; p. 673). "La vida [del espíritu] es para-sí, un alma" (Ibid.). La vida, en último término, "es el concepto de la vida que ha retornado en sí, es el devenir del concepto ... que existe como universal" (p. 473-474; p.674). Intersubjetivamente esta vida es "el proceso del género humano" (prozeß der Gattung), como la "verdad de la vida", es decir, "el género [humano] retorna para-sí (in sich zu rückkehrt)": es "el alma" (p. 488; p. 683).

El "espíritu", entonces, es la "idea de la vida" hecha acto. Por su parte "la idea de espíritu es un objeto lógico" (logischer Gegenstand) (p. 497; p. 689), "dentro de la pura ciencia" que busca la "realidad" (Realität) como algo "subjetivo", y esto es "el concepto teórico", el "conocer". "La verdad objetiva es la Idea misma" como "saber" (Wissen). En este sentido puede entendese que "lo objetivo está puesto como subjetivo" (das Objektive in das Subjektive gesetzt) (p. 499; p. 691). Es decir, el sujeto se conoce a sí mismo por la auto-conciencia y se hace objeto de si mismo es una reflexión absoluta. Esa "idea" hay que desplegarla y sería entonces el "concepto desarrollado" (entwicklelten Begriff) (p. 530; p. 711).

Para ello hará todo un rodeo por la "idea de bien", y el "impulso" como "voluntad" para alcanzar "la totalidad del concepto" (Totalität des Begriffes) (p.543; p. 719), como lo que se "determina a sí mismo" (Selbstbestimmende), como el "contenido" (Inhalt), como "particularización" (Besonderung). Sin embargo "le falta la conciencia (Bewußtseins selbst) ... el momento en que la realidad (Wirklichkeit) haya logrado el concepto para-sí como (auto-)determinación de su ser eterno" (p .545; p. 726). ¡Hay que dar el último paso de la reflexión absoluta del sujeto que tiene al sujeto como su objeto transparente! 
Llegamos así a la "idea absoluta", que es "un más allá (Jenseits) que busca y como un fin que no se alcanza" (urreichtes Ziel) (p. 548; p. 726). Y aquí hay que leer la últimas páginas de la Lógica en la que
Hegel alcanza lo que Wittgenstein llamaría "lo místico". "Esto lo realiza el método como un sistema de la totalidad" (ein System der Totalität) (p. 569; p. 738):

"La lógica ha vuelto (zurückgegangen) en la idea absoluta, hacia aquella simple unidad que es su comienzo (Anfang); la pura inmediación del ser en que al principio toda determinación aparece como subsumida o por la abstracción dejada de lado [...] Pero ahora es también un ser lleno (erfülltes Sein), o sea el concepto que se concibe a sí mismo, el ser como totalidad concreta [...] Esta idea es todavía lógica, está incluida en el puro pensamiento, y es sólo la ciencia del concepto divino (göttlichen Begriffs) [...] Vale decir, dado que la idea se pone como absoluta unidad del puro concepto y de su realidad (Realität) [...] el fin subjetivo se convierte en vida [... se convierte en] la ciencia en la relación del conocimiento divino (göttlichen Erkennens) hacia la naturaleza" (pp. 572-final; pp.740-final).

Por ello, el texto de Aristóteles (Metaf., xii, cap. 7, 1072 b 18-30), interpretado por Hegel y con el que termina la Enciclopedia, indica el remate final de la Modernidad:

"El pensar (noûs) ${ }^{18}$ se piensa (noeî) a sí mismo como lo pensado (noetoû) [...] lo mismo es el pensar (noûs) que lo pensado (noetón)[...] porque lo pensado (noetoû) es la substancia del pensar (noûs) [..] La actualidad (enérgeia) del pensar (noû) es vida (zoé) [...] Esto es lo divino (theós)".

Si tradujéramos este texto en terminología hegeliana diríamos, palabra por palabra, algo así como:

"El espíritu tiene un concepto del mismo espíritu como idea. Lo mismo es lo racional que lo real, porque lo real es el contenido del concepto. La actualidad (Tätigkeit) del concepto es la vida. Esto es lo divino". 
Comparemos este subjetivismo racionalista absoluto con la postura de un realismo crítico que nos permitirá recuperar la realidad de lo real como un de suyo que está más allá de la mera subjetividad como actualidad racional del cerebro humano: el espíritu de Hegel.

\section{La vida humana involucra constitutivamente a la inteligencia}

L

a tesis que queremos defender

racionalismo subjetivo absoluto, ya ante el racionalismo indicado, que lo intersubjetivo o discursivo y muy especialmente frente al debe subsumirse, es la siguiente:

"Una especie de idiotas sería inviable. La inteligencia es un factor biológico de la estabilización de la especie, como es un factor biológico de respuesta adecuada en cada uno de los individuos" (Zubiri, 1992, p. 213).

De otra manera:

"He aquí la primera descripción de la actividad de un ser viviente: Es independiente del medio y con control específico sobre él, para organizar unas respuestas adecuada en orden a la persistencia de sus sustantividad, en virtud de una situación que ha interrumpido aquel equilibrio deseable, porque si no tuviera suscitación ninguna se moriría como viviente [...] ¿Qué sería de un ser viviente, cuya perfección de vida consistiera en ser inaccesible a toda suscitación? [...] Este ser viviente habría muerto" (Zubiri, 1995, p. 172).

Se nos explica, además, que en este caso lo vida humana no es condición (de la inteligencia, razón o argumento, como para Apel, Miranda, Hegel o Mario Rojas), sino que es posibilitación, ya que la inteligencia o la razón argumentante son momentos intrínsecos del viviente humano (de la vida humana) y no meramente otra cosa (el alma o el espíritu) condicionada externamente por un cuerpo que le acontece "estar vivo", pero no como la "vida del espíritu".
Para ello es necesario tomar la vida humana más en serio. Xavier Zubiri dedica unas buenas páginas al tema (Zubiri, 1995, pp.129-245). Comienza por describir que las cosas se "alteran" de diversas maneras. La primera es por "transformación" (físico química), por "repetición" (aquí estamos al nivel macromolecular del universo físico) (véase Dussel, 1977, 4.1), por "génesis" (el del phylum biológico). En efecto, la vida sobre el planeta Tierra manifiesta un nuevo tipo de "alteración" de la mismidad, 
que es dinámica. Se trata de la evolución de la vida, bajo la siguiente regla:

"La estructura viva adquiere, en cierto modo, el carácter de una distancia activa, que cuanto más viva sea más se separa del resto del universo [...] A saber: tiene una cierta independencia del medio, y cierto control sobre él. Ni que decir tiene que cuanto más vivo sea un ser viviente tiene más independencia del medio y más control específico sobre ese medio" (Zubiri, 1992, p. 165-165).

A esta entidad propia de la vida le llamaré la posición pragmática del viviente (pragmática no en la lingüística de Apel sino en el sentido griego de prágmata: la cosa a la mano prácticamente). Es decir, el viviente cuando más evolucionado sea tendrá más control sobre su medio para la persistencia o sobrevivencia del ser viviente. Más capacidad de "habérselas" con "las cosas, con los demás hombres y consigo mismo" (p. 225).

En esta línea reflexiva podrá entenderse entonces que la inteligencia o la razón (igualmente la voluntad y la afectividad o sentimientos) son modos extremadamente evolucionados de la vida para habérselas con el medio para controlarlo, manejarlo (managment) para la propia producción, reproducción y desarrollo de la vida (por ahora de la vida en general). En efecto, los vegetales se nutren (como todo viviente) pero no pueden controlar su medio como los animales. Estos tienen un sistema nervioso que les permite una muchísimo mayor competencia en ese habérselas con el medio. La "colocación" del viviente constituye al sitio donde se está como un medio. El viviente modifica el lugar y lo transforma en un medio más adecuado para la vida (desde "la tarea" efectuada por las bacterias preparando las condiciones para la vida propiamente dicha, produciendo por ejemplo el oxígeno de la atmósfera; en el viviente superior ese medio creado será la cultura humana). El medio es ecológico.

El sistema nervioso de los vivientes evolucionará constatando el medio para nutrirse por medio de simples estímulos. En el cerebro de los primates, en los euhomínidos y finalmente en el homo la vida, como vida humana, alcanzó el máximo de independencia del medio, el máximo de control o manejo de la realidad como realidad. El modo viviente de la realidad humana quedó dotada de una capacidad inteligente (de actualizar neuronalmente la realidad como realidad: la verdad) y volitivaafectiva (de amar la realidad como realidad: la fruición o gozo) que el permite el máximo de suidad: estar dotada de una subjetividad libre. 
Este modo de realidad viviente, inteligente y volitivo le permite ejercer

el máximo ejercicio del ser viviente como viviente:

"El viviente es aquella realidad, cuya forma de realidad consiste en darse a sí propio su propia mismidad [...] Un sujeto a quien acontece efectivamente el estar vivo, el ser vivo" ( $p$. 188-189). "La vida no es algo que constituye al viviente por sí misma, así, en su vitalidad dinámica, sino que, al revés, el viviente es realidad en vida" (p.192).

La vida humana, como unidad radical constitutiva (debajo de la inteligencia-sintiente o razón y de la volición-afectiva), es el todo dentro del cual ambos aspectos (in- teligencia y volición) son momentos internos, posibilitados. $Y$ esto porque la vida humana es el máximo de suidad (modo conciente-volitivo de reflexión):

"El ser viviente es siempre el mismo. La unidad radical y fundamental del ser viviente es la unidad dinámica de ser el mismo. El de suyo, propio y característico de toda realidad, se plasma justamente en el ser viviente en un modo especial de ser de suyo [...] Es de suyo él mismo. Y precisamente éste es el dinamismo de la mismidad como modo de realidad activa por sí misma" (p. 193).

En el Egipto el dios Ptah, el dios dador de la vida, tenía como sus componentes a Horus, el corazón (lo que llamaremos la volición-afectiva), y Toth, la lengua (la palabra, la inteligencia, la razón). El racionalismo sustancializa a Toth, el voluntarismo o materialismo ingenuo a Horus. Ambos son momentos de Ptah.
En el ser humano la vida humana llega al paroxismo del de suyo (aspecto reflexionado hasta la obsesión por E. Levinas: el de suyo del Otro), como independencia de la subjetividad libre, autónoma (que puede constituirse desde la heteronomía de la alteridad), que culmina en la posibilidad de la acción, como un dar de sí propio de la fecundidad de la vida en su vitalidad:

"El viviente nunca es lo mismo precisa y formalmente para ser siempre el mismo. Vivir por esto no es cambiar, sino devenir, dar de sí, en el sentido más estricto del vocablo [...] Se trata de que, si la realidad está constituida por un positivo de suyo, el de suyo de un chimpancé es mucho más rico y profundo que el de suyo de una ameba" (p. 200). 
El ser humano no sólo es el único que actualiza intelectivosentientemente lo de suyo de lo real como realidad, y no sólo es el único -como veremos- que ama con una volición-afectiva a la cosa real (o a otro ser humano, o a la comunidad) que le deja ser de suyo (amor de realidad), sino que además se hace cargo de la realidad (autoconciencia responsable) para poder transformar la misma realidad por el dar de sí (creando no ya un medio físico sino un medio cultural intersubjetivo):

\section{"Al hacerse cargo de la realidad, en virtud de esa función, las cosas no se presentan al hombre como medio sino como mundo" (p.206).}

Ahora se puede continuar leyendo a Heidegger, a Levinas, etc., corrigiendo lo que haya que corregir, desde la realidad de la pobreza de los explotados en el capitalismo (y de allí la importancia de Marx, el materialista -en el sentido que la vida humana es el contenido, la materia de todo acto humano, ecológico, económico o cultural), del mundo poscolonial, desde la mujer violentada, desde la razas no blancas discriminadas, desde los marginales, etc.

\section{La volición-afectiva o el sentimiento-volitivo momentos esencial de la vida humana}

$\mathrm{E}$ racionalismo (que sitúa a la subjetividad racional, el yo pienso, la racionalidad en cuanto tal, la conciencia, la autoconciencia, etc. como el momento central de la esencia humana) olvida que el acto volición-afectiva es tan esencial como el momento cognitivo, y se codeterminan sin última instancia. Cuando prima la racionalidad se cae en el racionalismo (desde Tomás de Aquino hasta Kant o Apel). Cuando priva la volición se cae en el voluntarismo (desde Duns Scoto hasta S. Freud). La vida ha constituido ambas instancias, en el proceso de la evolución del sistema nervioso-cerebral, para que la vida humana pueda beneficiarse de ambas facultades simultáneamente, sin posible prioridad de una sobre otra. El "sistema límbico" (el aparato neuronal volitivo-afectivo) comienza a descubrirse en el presente, y debe articularse con el "sistema neocortical" y "frontal" (el momento de la inteligencia, racionalidad teórica y práctica) del cerebro, para lograr una nueva comprensión de estas dimensiones intrínsecas a la vida humana. La vida humana no es un "Leib a priori" (como le llama K.-O. Apel), ni una condición genética temporal externa (como lo formula Mario Rojas). De ninguna manera, la vida humana es el todo constituivo 
dentro de la cual la inteligencia y la volición son facultades subsidiarias de la vida humana ("factores biológicos" le llama Zubiri en texto citado arriba).

En efecto, el acto volitivo, como el intelectivo, pertenece a la unitaria corporalidad viviente humana y no puede separarse los volitivo de lo sentimental (las emociones primarias, secundarias y las evaluaciones global cerebrales son todas humanas subsumiendo unas a otras unitaria- mente) (véase A. Damasio, 1994 y 2003; Dussel, 1998, § 1.1).

Cuando Marx comienza su vida crítico intelectual de manera frontal, en el 1844 en París — cuyo testimonio son los Manuscritos del 44-, se enfrenta a Hegel con un escrito antropológico-económico, en el que el ser humano es descrito desde la vida y como necesidad $-y$ yo comienzo con esto texto el tratamiento del llamado "principio material de la ética" (Dussel, 1998, § 1.5 [101]-:

"Por tanto, por una parte, el ente (Dasein) que Hegel subsume (aufhebt) en la filosofía no es la religión, el Estado o la naturaleza reales (wirkliche), sino la religión misma ya como objeto del saber, es decir, la dogmática, y así también la jurisprudencia, la ciencia del Estado, la ciencia natural" (Marx, 1956, t. 1, p.583).

Esta interpretación de Marx se opone a la del último P. Miranda, de M. Rojas y a la de Jorge Antonio Pardo (lo siento, pero estoy de acuerdo con Marx, y ¡no estoy mal acompañado!). Para recuperar la realidad Marx debe contar con un criterio de verdad fuerte: la vida humana:

"El ser humano real (wirkliche), corporalidad (leibliche), en pie sobre la tierra firme [...]. El ser humano es inmediatamente ser natural. Como ser natural, y como ser natural vivo (lebendiges), está, de una parte, dotado de fuerzas naturales, fuerzas vitales (Lebenskraeften) [...] como impulsos (Triebe); de otra parte, como ser natural, con corporalidad sensible, objetiva, es, como el animal y la planta, un ser vulnerable (leidendes, aspecto recalcado por E. Levinas), condicionado y limitado, esto es, los objetos de sus impulsos existen fuera de él" (Ibid., p.577-578).

Marx se encuentra en el mismo nivel de la descripción zubiriana cuando escribe:

"Físicamente el ser humano vive (lebt) sólo de productos naturales, aparezcan en forma de alimentación, calefacción, vestido, vivienda,19 etc. [...] Que el hombre vive en la natu- 
raleza quiere decir que la naturaleza es su corporalidad, con la cual ha de mantenerse en proceso continuo para no morir [...] La actividad vital, la vida productiva [el dar de sí de Zubiri] misma, aparece [esta es la función de la inteligencia o la razón] ante el ser humano sólo como un medio para la satisfacción de una necesidad [...] Es la vida que produce la vida" (p.515-516) $)^{20}$.

Las necesidades humanas ("del estómago o de la fantasía" dirá Marx en El capital I, 1) se encuentran en el ámbidsto del mundo tendencial, afectivo. Radicalicemos ahora la reflexión en un nivel metafísico.

Así como la inteligencia puede actualizar (neocorticalmente) la cosa real como realidad, como de suyo, de la misma manera tendencialmente puede apetecer, puede estar tensionado volitivamente hacia lo real como querido, como lo amado de suyo, por sus propias cualidades reales; en el caso de otro ser humano por su propia dignidad (fundamento de todo valor); es un fin de fines en el ordo amoris (diría Max Scheler) que es distinto del ordo cognoscendi. El sentimiento-volitivo o la voliciónafectiva son tan humanas como el sentido-inteligente y la inteligenciasentiente. Pero el inteligir es cognoscente (actualizante cerebralmente) de lo real, mientras que la volición es fruición o satisfacción (conmoción físico-cerebral como estado corporal) de lo real.

Por el sentimiento-volitivo el medio es constituido como valioso o como "posibilidad" -en un sentido aproximado al de Heidegger en Ser y tiempo-:

"La realidad como posibilidad de su realidad plenaria es aquello que constituye el término formal del acto de volición. La posibilidad no coincide con la realidad. Hay muchas realidades cuyas propiedades son conocidas, y que sin embargo no funcionan siempre como posibilidades de la vida del hombre" (Zubiri, 1992, p.37).

Es decir, "la volición incluye como ingrediente esencial lo desea-

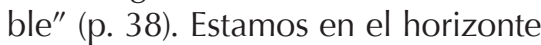

de A. Schopenhauer, de F. Nietzsche, de S. Freud, sin coincidir con ninguno de ellos plenamente.

\section{5. ¿Hacia una fundamentación ético-metafísica de la obligación del producir, reproducir y aumentar la vida?}

La plenitud de la vida humana es su realización acabada; en ese acabamiento se encuentra la satis- facción, la alegría, lo que Zubiri llama al fruición. Es el fruto del amor, siendo que "el amor, en tanto que 
amor, y formalmente, no va más que a la realidad en tanto que realidad" (p. 42). Y aquí con encontramos nuevamente con E. Levinas, en el tema del "deseo metafísico".

Ya Schopenhauer había expresado que el "querer-vivir" es la voluntad. Zubiri lo profundiza: "La voluntad es el acto de querer" (p. 53). En tanto tiende o apetece; en tanto se autodetermina, y en cuanto pone los actos para realizar la vida (haciéndola permanecer y aumentándola como plenitud, donde se alcanza la fruición). La certeza del conocer no es la fruición del querer; ambas son referencia a la realidad de lo real, a lo de suyo, como consistencia que por la actualización se controla (para la vida humana) o como apetecible que por la satisfacción atrae primero y regocija en su cumplimiento (la vida gozosamente desarrollada). En el querer del ser humano ante otro humano la suidad (lo máximo posible de lo de suyo, su exterioridad) es constatada como cara-a-cara, piel-apiel, en el encuentro con lo amado como otro (otra), como realidad querida (no sólo conocida). Sólo en el ser humano puede darse entonces este sentimiento-volitivo o esta volición-apetitiva, los animales sólo tiene apetitos o emociones primarias, sensibles. No tienen la plenitud de la "capacidad de querer" (p.55).

La vida humana es la raíz del acto intelectivo (o racional) y del acto volitivo, y "la unidad de la vida del hombre es absolutamente unitaria en su raíz misma" (p.67).

Por el modo de realidad en el que consiste la vida humana, no es solo cognoscente o racional, sino siempre también es un ente volente de las cosas reales (y los otros seres humanos) como realidades de suyo, con consistencia física (en cuanto inteligidad) y como amables (en tanto queridas). Y escribe Zubiri -muy próximo a E. Levinas en Totalidad e Infinito-:

\begin{abstract}
"El hombre que quiere una cosa, se realiza él en aquella cosa, por ejemplo, el hombre que come un filete está haciendo por la vida [...] El hombre es llevado por las tendencias, en una situación determinada, a tener que enfrentarse con las cosas como realidad" (Pp. 70-71).
\end{abstract}

Ese ir tendencialmente originario hacia las cosas, en cuanto exigidas para la reproducción y crecimiento de la vida son primeramente necesidades - de las que Zubiri no nos habla, sino sólo de "preferencias", sobre lo que F. Hinkelammert nos ha advertido la diferencia-. El ser necesitante, para Levinas, no es todavía el "encuentro ético", sin embargo integrando Zubiri con Levinas y Marx, podemos entender que el tender hacia la cosa real como posibilidad de negar la negación del hambre (lo necesario para la vida humana), captando al alimento como nutritivo de suyo y por lo tanto querido, valioso (con valor de uso) ciertamente no es 
el amor de responsabilidad del Otro como otro, como de suyo libre y por lo tanto lo más real en su realidad de todo lo que nos enfrenta en el medio, en el mundo, pero sin embargo es objeto de una tendencianecesitante del alimento, no como el objeto de un mero estímulo animal, sino como lo que sacia el hambre humano, en comunidad, en el banquete, en la fiesta, en el uno junto a los otros como fruición del comer en la alegría de la celebración. Es un comer humano, cultural, lingüístico, histórico.

"Juan, que es un sujeto viviente humano responsable, está comiendo" escribimos en nuestra Ética de la Liberación (Dussel, 1998, [110]). Ese enunciado es empírico, porque se trata de algo constatable como acto descriptivo; pero además es un enunciado que contiene una dimensión ética, porque la "responsabilidad" -que no puede faltar como nota en la naturaleza de un ser humano como "Juan"- es posible por la autoconciencia y la libertad -esta última momento de la estructura del sentimiento-volitivo humano, que puede guardar distancia ante las posibilidades que funda el proyecto existencial (diría M. Heidegger, el Entwurf) que la vida humana diseña (funciones que se sitúan en la región frontal del cerebro), pero de las cuales posibilidades ninguna puede ser perfecta o plenamente satisfactora de la capacidad sentimiento-volitiva humana insondable. Es por la finitud de las posibilidades que enfrentan a la capacidad volitivo-apetitiva que ésta puede permanecer libre, responsable y éticamente enfrentada a la cosa real.

En este sentido, ya, el poder-ser como proyecto adviniente, futuro, obliga al ser humano a cumplirlo, porque es el fundamento de las indicadas posibilidades o objeto de las decisiones éticas. En este sentido desde el ser-adviniente (como poderser heideggeriano) se impone ya como obligación al sujeto humano en el mundo. El ser como futuro funda las posibilidades en su deber-ser. Debemos cumplir con el proyecto ontológico, porque se nos impone como los libremente intentando en toda acción humana en tanto humana, es decir, en tanto libre $y$ responsable. A diferencia de los actos necesitantes de los instintos, que rigen por naturaleza, el régimen del proyecto funda la obligación ético ontológica como obligación.

Pero esto no es todo ni principalmente. Cuando nos enfrenta en el mundo esa cosa real que es alguien, pasamos a lo que fríamente Zubiri llama res eventualis, y que E. Levinas describe fenomenológicamente de manera sui generis y genialmente. Para Levinas, la aparición del Otro es la experiencia ética por excelencia. El "deseo metafísico" (la volición-apetitiva suprema, el ágape, más allá de la philía y el éros) el Otro (la Otra) es el ejercicio esencial mismo del sentimiento-volitivo cuya capacidad de amar al Otro (como lo real por excelencia, porque constituye lo de suyo bajo la facultad de ser libre, incondicionada con 
respecto a la subjetividad viviente volente) lo constituye a sí mismo como su suprema realización y fruición: "¡Ama al Otro [como otro, como de suyo, porque ese amor te constituye] como ti mismo!" El "sí mismo" volente del ser humano en su paroxismo se alcanza en el amor al Otro. El amor nos mueve a asumir al Otro, a asumir su felicidad y su dolor. Esa mutua responsabilidad por los Otros, lo supremamente de suyo, entrelazada por la intersubjetividad constituye la comunidad.

Por la comunidad, además, podrá entenderse ahora que la vida solipsista es imposible. Que todos somos parte de una comunidad que nos antecede, que no procrea, que nos cobija, nos alimenta, que nos da la lengua, la cultura, las narrativas míticas. La vida humana que hemos recibido sin ningún mérito previo, porque es imposible merecerla (antes de ser engendrados como lo pretendía J. P. Sartre, y que M. Merleau-Ponty muestra su contradicción), como deudores inevitables entonces, macehuales (en el sentido azteca de la finitud), nos enseña el respecto a la vida humana que tiene dignidad absoluta. Pero esa dignidad no se descubre, ni se funda primeramente como un presupuesto transcendental de la argumentación (momento racional de la vida humana), sino que se descubre y funda primera y metafísicamente por la existencia misma de la vida humana y del ser humano como ser inteligente (antes que racional) y como ser volente que tiende a la misma vida plenamente realizada como fin último, y en esto consiste su dignidad (no teniendo valor, por ser el fundamento de todos los valores21)

La imposibilidad ética del suicidio (no su posibilidad empírica) viene probada en aquello de que nunca podremos desentendernos de la obligación que nos sobreviene por el siemple hecho de haber recibido de los otros nuestra vida. Nunca podremos afirmar que ya hemos podido cumplir con las responsabilidades (obligaciones o exigencias como deberes del potencia suicida ante los derechos de los otros) de los que están a nuestro cuidado. El suicida podría decir empíricamente que: "iEsta vida no vale la pena de ser vivida!", sin embargo, muchos otros tiene derecho a recibir de ese potencial suicida aquellos actos de los que no puede negarse a cumplir por ser su deber para con ellos. El padre suicida ¿cómo podrá saldar su deber para con su hijo que trajo a la existencia y que no ha terminado de proteger y educar? ¿Quién dará a su mujer el amor y el cuidado al que se comprometió al acordar constituir una pareja? ¿Quién acogerá a sus viejos padres en su hogar para que no deban mendigar por las calles por la ausencia de su hijo suicida? ¡Nunca nadie podrá saldar todos sus deberes ante todos los miembros de la comunidad (en último término de toda la humanidad) para que libre de dichos deberes pueda éticamente (porque físicamente es siempre posible) quitarse la vida! 
El deber de conservar y aumentar la vida humana se funda, y es ya un modo de fundamentación intersubjetiva, metafísica, en el hecho de que una vez que la hemos recibido gratuitamente en comunidad quedamos atrapados (podríamos decir) a ser inevitablemente participantes intersubjetivos de una red de obligaciones, de deberes, de responsabilidades, de normatividad ética con respecto a la vida humana misma.

Ese deber con respecto a la vida humana no es sólo un cumplir aquello de que "el don gratuito recibido con gratuidad se paga"; sino el hecho éticamente objetivo de que el viviente humano, volente libre y responsable de su vida, la "tiene-a-cargo"22 como obligación de pleno cumplimiento. $Y$, además, por su pertenencia comunitaria e intersubjetiva, esa obligación no es sólo solipsista sino realmente comunitaria. Somos responsables de los otros sin los cuales no hubiéramos sido reales, no hubiéramos recibido la vida, y no lo seremos en el futuro de la comunidad y de la especie humana como totalidad. El suicida es un irresponsable, porque éticamente es un deudor que no paga su deuda; por ello es un sujeto injusto, éticamente reprobable. Puede empírica o fácticamente suicidarse, pero no podrá fundar su suicido éticamente, ni llevarse a la tumba el recuerdo de una comunidad que lo recuerda como a los héroes: los que dieron su vida por la vida de la comunidad. El dar la vida por la vida no es suicidio injusto. El suicidio injusto es la afirmación solipsista sin referencia a los deberes para con aquellos que merecen todavía nuestro servicio. No puede fundamentarse éticamente.

\section{6. ¿Fundamentación del principio discursivo?}

Situados ahora en el horizonte abstracto de la racionalidad humana (en el de la inteligencia-sintiente en primer lugar), el de la razón discursiva (es decir, en el campo epistémico aún de la filosofía) y sabiendo que el ser humano es un ser racional (no sólo racional, y por ello hay otros principios que el sólo discursivo), y no sólo en cuanto razón teórica sino como razón práctica o ética, debemos afrontar la cuestión de la fundamentación (o del dar razones o argumentar a favor) de la racionalidad misma contra un oponente radical, el escéptico, que niega a la misma facultad de la razón o su posibilidad argumentativa; es decir, hay que dar razones acerca del deber de argumentar teórica, y más específicamente de la razón práctica, éticamente. En este sentido restricto y abstracto, es decir, situándome en el horizonte de la racionalidad humana misma (una dimensión de la vida humana, vida que juega como el todo dentro del cual se encuentra la función de la racionalidad), puede afirmarse que todo el que "formule o sostenga" 
alguna objeción a la racionalidad o a la posibilidad de la argumentación "se encuentra ya siempre en el ámbito del discurso lógico-racional, filosófico argumentativo, de la justificación de la validez, pues con sus tesis entabla pretensiones universales de validez frente a todo otro posible ser pensante-argumentante" 23 . En cuanto tal, como miembro de una comunidad de argumentantes, como subjetividad racional, conciente $y$ autoconciente, presupone ya siempre que todo miembro de una tal comunidad deben ser reconocidos como iguales, sustantivamente en su dignidad (para que se tenga simetría como punto de partida de toda argumentación, y con ello se presupone una connotación material, en el argumento de Mario Rojas, no sólo formal como para Apel). Esa igualdad de dignidad debe siempre presuponerse trascendentalmente para poder argumentar racionalmente.

De esta afirmación pueden deducirse todos los deberes del ser humano como ser raciona y también sus derechos.

Desde esta posibilidad de deducción racional, como racional, se pretende ahora definir como meras condiciones: "ciertas necesidades vitales imprescindibles básicas, es decir, las referentes a la condición vital sustantiva de todo sujeto, a su existencia como viviente" (Ibid.). Se deducen así de la fundamentación racional del ser argumentante como sus condiciones necesarias las necesidades básicas de la vida humana. Es decir, la esencia humana sería un "yo argumentante" espiritual el cual debe cumplir con las necesidades vitales como condiciones de la argumentación. El todo (la vida humana según lo que hemos expuesto arriba) se sitúa simplemente como condición de la parte (en una visión no racionalista de la racionalidad). Sería algo así como situar al cuerpo todo (la posición del racionalismo) como una condición cuasi-externa de la existencia de la mano. Hemos mostrado que la realidad humana nos sitúa exactamente en una posición contraria: en primer lugar, a) la corporalidad humana viviente, el modo de realidad de la vida humana, fundamenta el deber vivir desde la misma vida (como proyecto humano, como vida comunitaria, y de otras maneras, contra el suicidio), $y$, en segundo lugar, b) racionalmente fundamenta lógico-abstractamente y como pretensión de validez a la misma racionalidad humana.

¿En qué sentido puede decirse que "la razón es obligatoria en sí misma para el ser humano?: [en el sentido que] se debe ser racional, [que] debemos ser racionales" (Ibid., parágrafo 16).

Una vez concedida esta formulación, deberíamos aún dar un paso más (para no quedar nuevamente apresados en un puro horizonte racionalista) ¿No puede tornarse materialmente (por su contenido) irracional una totalidad, un sistema o una argumentación (que puede ser lógica o racional en cuanto a su coherencia formal)? ¿Cuándo Aristóteles demostraba que "el esclavo era 
por naturaleza esclavo" o cuando el capitalismo demuestra como racional una inversión que "aumenta la tasa de ganancia", no hay que recurrir a un criterio fuerte de verdad como la vida para juzgar que un tal sistema se ha tornado irracional? ¿La irracionalidad de lo racionalizado no tiene que contar con la vida como criterio de verdad que fundamenta a la misma razón? La racionalidad de la razón no es sólo la formal coherencia de la razón argumentativa, sino igualmente tiene por fundamento la afirmación de la vida humana y de su desarrollo integral, es decir no sólo (siempre también) parte de la fundamentación racional, sino igualmente del cumplimiento volitivo-sentimental, y de la vida humana como el modo de realidad dentro de la cual la racionalidad es una dimensión (importante, pero no única).

El intentar fundamentar (o justificar) la eticidad de todas las

acciones humanas exclusivamente por deducción lógico-formal del principio racional (sea procedimental normativa como para K.-O. Apel; cuasi-sustantivo por reconocimiento de la dignidad para Mario Rojas, o a partir de la intersubjetividad en $\mathrm{P}$. Miranda) en cuanto cumplimiento de deberes y derechos, caería inevitablemente no sólo en un racionalismo formalista (como cuando Kant en La metafísica de las costumbres reduce la ética y la política a virtudes y derechos) sino, para expresarnos como S. Kierkegaard, en lo "cómico". ¿Cómo deducir como deber o derecho el amor de una mujer o un varón a su pareja desde la obligación de procrear nuevos argumentantes para una comunidad de comunicación futura? Ese amor tiene la sustantividad propia del ordo amoris que hay que intentar fundamentar materialmente.

Repitiendo, escribe Mario Rojas:

"Si bien es absolutamente ético satisfacer las necesidades vitales básicas imprescindibles, mantener la vida de seres humanos sólo en ese nivel no lo sería. La meta de la vida del ser humano no es su mera permanencia y conservación en la existencia meramente física orgánica, ella deber ser por el contrario desarrollada en el sentido de llegar a ser una vida racional autónoma en su constitutiva relación intersubjetiva" (Ibid., parágrafo 18).

Obsérvese que se habla de "sólo", "mera" o "meramente física". Es decir, se está pensando dualistamente en un cuerpo biológico y en actividades superiores racio- nales, espirituales contrapuestas. Hay un cuerpo y un alma. Si por el contrario se comprendiera que las necesidades vitales están incluidas y son ya siempre necesidades cul- 
turales y hasta místicas y religiosas, como momentos de la vida humana, donde el momento racional cumple una función, como una necesidad (superior) de la vida humana (la de conocer lo real para manejarlo en vista del aumento cualitativo de esta vida humana, es decir, siempre también espiritual), se entendería que la vida humana no es "meramente física orgánica", sino que es el todo dentro del cual el momento de la vida racional es una parte constitutiva. Momento universal de la vida racional que debe fundamentarse ante el escéptico, relativistas o particularistas que elevan a su particularidad como pretendida universalidad (el eurocentrismo, por ejemplo). A dichos oponentes a la racionalidad humana hay que saber refutarlos racionalmente en nombre de la vida negada de los oprimidos (excluidos también de la comunidad de comunicación), y de allí la necesidad de un universalismo racional (pero no racionalista) en donde el dominador pueda aceptar por argumentación (o por otros medios éticos, cuando los argumentos se hayan agotado, como la "lucha por el reconocimiento", hasta el "estado de rebelión") o por recursos lógicos que se encuentran en el mismo sistema global en el cual el dominador es culpable de la injusticia sufrida por el Otro ${ }^{24}$.

\title{
7. La posición filosófica de Ignacio Ellacuría acerca de la vida humana
}

En este debate, y de manera frontal, intervino avant la lettre, Ignacio Ellacuría. El tema de la vida fue central en su pensamiento desde su juventud. Deberemos dejar para otro ensayo el problema propiamente de la fundamentación -para no extendernos en demasía-. Aquí trataremos entonces la cuestión de la vida humana, como su presupuesto. En 1956 (a sus 26 años) escribe un artículo sobre Ortega y Gasset, y lo cita:

\begin{abstract}
"Yo soy mi vida, y mi vida no es puramente mi yo entendido en el sentido consueto, sino que es el yo y las cosas [...] Esta unidad de dinamismo dramático entre ambos elementos -yo y el mundo- es la vida"25.
\end{abstract}

Una y otra vez vuelve sobre el tema, ya que "en Ortega ese fondo es un afán de vida. Pero de vida racional. Un afán de razón, pero de razón viviente. Necesidad de claridad sobre la vida y necesidad de vitalismo sobre todas sus claridades, exasperada forzosidad de vivir, de sentirse vivir bajo el signo de la luz y la razón" ${ }^{\prime 26}$. La obra de Ortega, comenta Ellacuría: 
"Estará coloreada con nuevos matices en el intento de evadir el historicismo relativista y el vitalismo irracionalista, pero la razón viviente y la razón histórica serán fundamentalmente un buceo en los abismo de la propia vida" ${ }^{\prime \prime 2}$.

Y repite nuevamente, hablando siempre de Ortega:

"En el vivir y en el pensar de Ortega hay una preocupación radical: la de la vida y de la cultura [...] Entre los dos, el elemento primero y fundamental es la vida". ${ }^{28}$

Es interesante que Ellacuría, para salvar a Ortega, indica que "el vitalismo biológico se transforma [con los años] en vitalismo humanista" ${ }^{\prime 2}$. De todas maneras se recalca que para Ortega "la cultura va regida $p$ or la vida como tal" ${ }^{\prime \prime}$.

Al final de sus juveniles reflexiones estéticas sobre Ángel Martínez, concluye:

"En busca siempre de la palabra de Vida; flor de vida y fruto de vida: también su semilla. Palabra que no es sino el último paso de la vida entregada a la Vida [...]; palabra que intenta originar más vida [...]; palabra que por nacer de la vida y de la Vida no tiene más pretensión que despertar luminosamente en los otros la vida y la Vida"31.

En polémica ante Santiago Ramírez, se pone de lado de la "filosofía vitalista moderna"32, que en un momento de su valiente crítica al tomista (extremadamente estricto y versado, pero totalmente desequipado en filosofía contemporánea) escribe:

"Paralelamente, querer aludir a loa misma realidad mentada por Ortega cuando habla de la vida con la distinción de vida en acto primero y en acto segundo [...] es probar una vez más el desenfoque con que Ramírez se presenta en casi toda ocasión ante Ortega. Este parte de una vivencia personas para la que está capacitado como pocos y que formuló frecuentemente: el caso es que asíllevamos trescientos años, y que todos los estudios naturalistas sobre el cuerpo y el alma del hombre no han servido para aclararnos nada de lo que sentimos como más estrictamente humano, eso que Ilamamos cada cual su vida [...] $]^{33}$; se ha dado cuenta que los hechos y los individuos se le escapan a la razón pura, que la vida concreta de cada quien, por sus dos extremos de vida y de concreta, no aparece próximamente clarificada en ninguna de las filosofías de tipo racionalista" ${ }^{\prime \prime 34}$. 
Mostrando Ellacuría su proyecto filosófico, se propone mostrar la posible "conciliación" "entre la filosofía perenne y la filosofía vitalista y existencialista" ${ }^{\prime 35}$. Así, por ejemplo, si se toma al "yo", que en la escolástica es una hipóstasis sustantiva y en Ortega un proyecto existencial, Ellacuría concluye -en fórmula que pudiera ser aceptable para ambos:

"Tendríamos así un pensamiento cuyo esquema podría ser: nuestro yo-hipóstasis, frente al mundo que lo oprime ${ }^{36}$ y con el cual necesariamente tiene que habérselas, constituye su vida que debe alcanzar la medida del yo-ideal, que es su auténtico yo, el que debe ser" ${ }^{\prime \prime 3}$.

Lo que se deja ver es que Ellacuría no puede aceptar el racionalismo, sin dejar la precisión metafísica (que encontrará en $\mathrm{X}$. Zubiri su máxima expresión), y por ello absorberá las tesis fundamentales del vitalismo, sin caer en relativismos o irracionalismos. Es un vitalismo metafísico en ciernes ${ }^{38}$. Esa capacidad asuntiva, positiva, de lo no tradicional se manifiesta en la indicación de que toda crítica al régimen soviético debe comenzar siempre viendo los aspectos positivos de esa enorme revolución ${ }^{39}$. Describiendo las miserias del pueblo ruso escribe Ellacuría que "fue este mundo dolorido el que recogió en sí el marxismo, el que despertó un dinamismo indomable en los luchadores de la primera hora" ${ }^{\prime \prime 4}$.

No extrañamente Ellacuría recurre también a Henri Bergson, el gran vitalista del comienzo del siglo XX. Bergson, como Ellacuría, se oponían al positivismo (uno de finales del siglo XIX, otro de mediados del siglo XX, lo mismo que P. Miranda), pero la cuestión no estribaba, como en el último nombrado, en negar la materia, sino en recobrar desde la vida la esencia de la subjetividad (como Bergson y Ellacuría):

"Cuando el hombre se deja dominar por la inteligencia [contra el racionalismol en cuanto es una facultad dada para el domino de la materia y para la eficacia de la acción material, en cuanto concibe todo el mundo de modo mecanicista, material y estático, desconociendo lo que el ser tiene de específico, que es la vida, el movimiento, la duración, da lugar a una forma de vida empobrecida y deshumanizada, tanto en el pensar como en el actuar ${ }^{\prime \prime 11}$

Comentando la obra célebre de Bergson, Las dos fuentes de la moral y la religión, muestra primero una crítica a la moral y religión "es- tática", para después comenzar el momento dinámico (¿nuevo presagio del pensamiento de liberación?): 
"La preocupación capital de Bergson como filósofo es la realidad y el problema de la vida: ¿por qué la vida ha alcanzado el nivel del hombre, cuando en otras muchas de sus manifestaciones se ha quedado tan atrás?; ¿cómo le será posible al hombre impulsar la potencia de su vida hasta su más alto rango posible? El hombre, para Bergson, no es sino la más egregia detención del torrente vital; la gran corriente de la energía creadora se ha lanzado a través de la materia"1/42.

Y adoptando una posición profundamente vitalista, que es la de Ellacuría hasta su muerte, muestra la dimensión espiritual de la misma vida humana, cuando indica que "para Bergson, este contacto vital con el principio de la vida es el misticismo ${ }^{\prime \prime 4}$, mostrando así que la experiencia mística es una dimensión sublime de la vida humana (no de algo diferente a la misma vida del ser humano, sino una última dimensión en continuidad con todas las restantes notas). Citando una vez más a Bergson:

"La perfección del misticismo es una toma de contacto y, por consiguiente, una 'coincidencia parcial con el esfuerzo creador que manifiesta la vida ${ }^{\prime \prime 4}$

Este largo artículo sobre Bergson, nos manifiesta, lo mismo que el haberse inscrito en la tradición ortegeana (que continuará Zubiri), que ontológica o metafísicamente Ellacuría es un vitalista convencido -lo mismo que un Hinkelammert y yo mismo-.
En un hermoso pequeño artículo sobre "Filosofía en Centroamérica", mostrando las razones de la dificultad de un arraigamiento profundo de la filosofía en un medio tan extraño a su temática, muestra nuevamente su talante vitalista continuamente. Escribe:

"Será cuestión de transfondo y entrelíneas o, tal vez más profundamente, cuestión de pertenecer a la misma corriente vital de la que el libro no es sino objetivación parcial [...] Hay, con todo, otras razones más hondas que hacen difíciles los libros de filosofía, en Centroamérica, si es que quieren conjugar dialécticamente ser libros de filosofía con su imprescindible caudal de universalidad, y serlo para y en un determinado ámbito cultural, que no puede vivir como suyo, sino lo que nace de sí. También la vida exige aquí ser un proceso inmanente ${ }^{1 / 45}$. 
Y plantea la manera como comprende la producción filosófica concreta:

"No significa que el pensamiento filosófico sea una tarea superflua respecto del comportamiento vital, algo que se mueve en los linderos del puro juego mental y dialéctico, sino que, como momento capital suyo, incluye la actitud vital que lo posibilita como auténtica forma de vida y el conocimiento implícito que de la realidad metafísicamente se tiene, condicionado en parte por aquella actitud vital [...] El filosofar [...] es antes que todo, una forma de vida [...], una realización vital"46.

En sus meditaciones -de unas largas 103 páginas editadas: "Técnica y vida humana en Ortega y Gasset"- sobre la Meditación de la técnica de Ortega y Gasset, avanza decididamente sobre el tema de la vida (escrito antes de 1962, es decir, con menos de 32 años). Ellacuría ocupa un primer punto sobre el método47. Pero los puntos 2. y 3. se ocupa de la "vida humana" (ya que el "mundo" ha de ser el de la vida humana $)^{48}$. Desde el inicio escribe:

"Porque Ortega estaba ya en 1933 definitivamente instalado en la idea de la vida como clave fundamental de toda la realidad ${ }^{49}$ para el hombre" ${ }^{1 / 50}$.

Desde un inicio va directo al asunto:

"Mas inmediatamente aparece en el análisis de esta primera situación concreta de sentir frío - válida como tipo de otras necesidades similares, que si están originadas en parte por urgencias llamémoslas ${ }^{51}$ objetivas, lo están más radicalmente todavía por el deseo de vivir que tiene el hombre, donde ya aparece que es el vivir la necesidad más radical que tiene el hombre-aquella en que radican las demás necesidades: [el] vivir es, pues, la necesidad originaria de la que todas las demás son consecuencias ${ }^{521 / 53}$.

En todo lo que sigue, un magnífico texto de Ortega y un mejor comentario de Ellacuría se dejará ver lo que ellos mismos denominan un cierto "dualismo" entre las "necesidades objetivas, animales" (la vida animal o biológica) y la invención de necesidades humanas como "vida humana", superior, que nace de las anteriores pero las supera. Todo el tema reside en una cierta concepción de "dos" vidas, un tanto equívocas; una anterior, sobre la que se "separa" y se construye la "vida humana" propiamente dicha, a partir de una vida biológica de las puras 
necesidades animales. Para Zubiri, posteriormente, la vida humana es el modo de realidad del ser humano (que nunca es primeramente puro "existir") que subsume todas las notas de la vida animal. Pero en éste último caso hasta la más mínima célula, un cabello, es siempre y solo "vida humana". En el ser humano no hay una pisca de "vida animal", toda ella se ha trans-sustantivizado (por la evolución) es exclusiva vida humana. Desaparece el concepto de "necesidades objetivas o animales": siempre son necesidades humanas (no sólo del "frío" de un madrileño, sino también el "hambre" de un salvadoreño, son siempre humanas). En el sentido zubiriano, la vida, entonces, no es la necesidad radical, sino la raíz de todas las necesidades no siendo ella misma ninguna necesidad (ni radical), sino la condición de posibilidad de todas las necesidades (aún la necesidad radical de Agnes Heller). Pero, habiendo advertido el tema, volvamos a Ortega y el comentario del joven Ellacuría.

En efecto, la vida es ya un "deseo de vivir" y por él se manifiesta:

"El hombre vive porque quiere ${ }^{54}$. La necesidad de vivir no le es impuesta a la fuerza, como le es impuesto a la materia no poder aniquilarse. La vida -necesidad de las necesidades- es necesaria sólo en su sentido subjetivo; simplemente porque el hombre decide autocráticamente vivir. Es la necesidad creada por un acto de voluntad"55.

Y agrega Ellacuría que "Ortega no se refugia para explicarla en el instinto de conservación" ${ }^{\prime \prime 5}$. Lo que acontece, aclaro yo, que el tal instinto en el ser humano es "humano" y por lo tanto expresión humana del querer conservar la vida de manera instintiva (instintivamente "humana"), que para nada niega lo de "humana" de la vida. Y por ello se intenta demostrar lo de "humana" de la "vida humana" por "la voluntariedad como nueva determinación de esa necesidad radical que es vivir" ${ }^{\prime 57}$. Pero no es la voluntariedad lo que hace humana la "vida animal" del ser humano, sino que la vida humana es humana aún en lo no-voluntario, en lo instintivo, en lo biológico: es biológicamente humana en todos los momentos de todas sus células, de todos sus órganos, de su cerebro, de todos sus comportamientos: en la digestión, en el sueño, en la nivel voluntario, o conciente. El ser humano nunca simplemente come primero como un animal, sino que siempre come humanamente, subsumiendo el acto real, no objetivo o biológico del digerir calorías, proteínas, etc., celebrando el comer como un acto comunitario, cultural y hasta ritual, espiritual ${ }^{58}$.

De todas maneras, las páginas de Ellacuría son de un notable vitalismo humanista. Queremos anotar muchas expresiones de esa centralidad de la vida, aunque siempre ambiguas. No dice sobre el ser humano: 
"Su querer vivir no es, pues, querer satisfacer las necesidades biológicas o querer sentirlas como tales y nada más que eso. Lo que el querer vivir hace es que se acepten subjetivamente aquellas condiciones objetivas sin cuya satisfacción no va a ser posible un vivir que no tiene nada que ver con ese mundo de las necesidades biológicas" ${ }^{\prime \prime 59}$. ético:

La vida de la vida humana es como algo superior, posterior, "superfluo",

"Mientras el simple vivir, el vivir en sentido biológico, es una magnitud fija que para cada especie está definida de una vez para siempre, eso que el hombre llama vivir, el buen vivir o bienestar es un término móvil, ilimitadamente variable ${ }^{\prime 60}$

En efecto, cada especie tiene un modo de vida, y lo propio de la vida humana es, por las facultades superiores del cerebro, superar siempre sus límites como historia y cultura. Pero no es un más allá de la vida animal que constituiría como un estrato de su realidad misma. Es decir, "el simple vivir" humano ya siempre tiende a superar los límites, porque no hay un "simple vivir" animal en el ser humano como un límite inferior. El "buen vivir" es el modo cómo el ser humano vive todas sus necesidades, aún las más perentorias, como el comer, beber, vestirse, alojarse (cuatro necesidades humanas que se transforman en imperativo ético en Egipto, en el Cristianismo, en Marx y Engels, y en muchos otros).

"Zoológicamente, vida significa todo lo que hay que hacer para sostenerse en la naturaleza. Pero el hombre se las arregla para reducir al mínimum esa vida, para no tener que hacer lo que tiene que hacer el animal. En el hueco que la superación de su vida animal deja, vaca el hombre a una serie de quehaceres no biológicos, que no le son impuestos por la naturaleza, que él se inventa a sí mismo. Y precisamente a esta vida inventada [...] es a lo que el hombre llama vida humana, bienestar. La vida humana, pues, transciende de la realidad natural, no le es dada como algo dado [...] -comer, huir, nidificar, etc.-, sino que se la hace él, y este hacérsela comienza por ser la invención de ella"61.

Puede verse lo ya indicado. En el ser humano no hay nada de vida zoológica, repetimos; hay sólo vida humana siempre. La "trascendencia" es sustantiva, en el sentido que al te- ner el ser humano otra "esencia" (en el sentido metafísico crítico de Zubiri) se subsumen todas las funciones anteriores dentro de otra estructura genética. El ser humano, que tiene 
poco genes de diferencia con los primates superiores existentes, por tener un genoma distinto no tiene (y lo repetimos por tercera vez) ninguna célula ni comportamiento animal. Siempre es humano. El "nidificar" es distinto al "edificar-habitar", pero lo es igualmente en el "comer" o en el "huir"; todos son radicalmente (esencialmente) distintos. Se nos recuerda que Ortega ni se preocupa de negar como falso que haya un "cuerpo" y un "alma", pero sí se preocupa de indicar que las necesidades animales no son las humanas, pero estas suponen a aquellos en un cierto ámbito de su propia estructura biológica:

\begin{abstract}
"Como vida humana, antes de que intervenga el primer querer vivir, es un puro estar sumergido y anegado en la naturaleza [...] En este sentido preciso -explica Ellacuría- es un animal"62.
\end{abstract}

Hemos ya visto que esto no acontece de esta manera. Y la ambigüedad persiste en una expresión casi sartreana: "La vida no le es dada al hombre sino que tiene que hacérsela"63. Sí, si se trata de la vida humana con respecto a su proyecto, al que decide cumplir. No, si se trata de ser desde siempre, como el modo de su realidad, ser viviente y humano, el que me es dado inevitablemente y desde el que no puedo sino partir para inventar mi futuro, del cual soy en parte responsable. Pero, la vida humana, el modo de nuestra realidad, es lo dado por excelencia, y no vale invención alguna. La vida, y la vida humana en especial, no tiene valor (porque el valor es lo propio de una mediación hacia un fin), sino dignidad, la de los fines, que es mucho más que valor. La vida ni tiene valor ni es una necesidad, porque funda los valores y las necesidades (de todo tipo, desde las primarias, como el comer; como las sublimes, como la mística; pero el comer nutre por dentro la mística y la mística da más sabor al comer, porque son momentos sin discontinuidad de una misma vida humana). E. Levinas, en la fenomenología del "gustar el pan" muestra los fundamentos de poder cumplir la "justicia" en cuanto tal —las papilas gustativas de la sensitividad están relacionadas a la esencia de la ética, en sus sentido más espiritual- ${ }^{64}$.

De todas maneras, es una afirmación rotunda a la vida, a la voluntad de vivir, que heideggerianamente puede expresarse así:

"El hombre tiene que estar en el mundo si quiere vivir, porque vivir es ya de por sí estar en el mundo y es, además, la condición necesaria para sobre-vivir sin abandonar la condición de vida especial que viene dada o limitada por estar en el mundo"65. 
En el volumen 2 de sus Escritos filosóficos vuelve sobre el tema: "El hombre no es vivo por lo que hace, fuera de que lo que radicalmente hace el hombre es vivir [... Todo esto remite] a algo más hondo, a la vida como modo de ser del viviente [...]"66. "Poseerse como realidad en la realidad, esto es la vida [humana]. La vida no es lo se hace; esto es la forma de vida. La vida es autoposesión o autodefinición de sí mismo. Por ello el hombre tiene una sola vida con una triple dimensión: principal, fundamental y estructural [...]"67. "La versión del hombre hacia los demás -escribe en otro trabajo- es una versión que está biológicamente fundada"68.

En un artículo de 1979, sobre "Biología e inteligencia" se expresa así:

"El carácter biológico del comportamiento humano no es sólo evidente como hecho [...], no es una condición ni una causa, sino un momento estrictamente constitutivo de una única estructura [...] El hombre aprehende todo materialmente, pues lo aprehende todo impresivamente [...] Todo lo psíquico es orgánico" ${ }^{\prime \prime}$.

Y en su artículo ya nombrado "Fundamentación biológica de la ética" (1979) toca explícitamente nuestro tema:

"La razón última por la cual lo biológico debe intervenir en la fundamentación de la ética estriba en que lo biológico es momento constitutivo de la realidad humana[...] Todo esto quiere decir -aquí Ellacuría argumenta contra Miranda y Mario Rojas- que lo que es el hombre y lo que son sus comportamientos está no sólo afectado, sino constituido por lo biológico. De ahí que deba evitarse -y lo hemos argumentado en todo este artículo- la tentación idealista que ve lo biológico como algo de tal modo superado por lo racional, lo psíquico o la sociológico -según distintas escuelas- que representaría tan sólo algo puramente subordinado a otros elementos no biológicos. Y esto no es así. [...] La inteligencia humana es sentiente, la voluntad humana tendente y el sentimiento humano es afectante [...] Dicho en término más éticos: ni la persona humana ni el sujeto humano pueden ser persona ni sujeto más que de un modo constitutivamente biológico"170. 
Podríamos detenernos en muchos otros aspectos, entre ellos en su estética, pero abordemos ya su obra definitiva Filosofía de la realidad histórica (1991).

Se inicia con un capítulo sobre "La materialidad de la historia"71 -en oposición radical del P. Miranda definitivo-. A favor de la materialidad, pero no del materialismo ingenuo o dogmáatico nos dice que "Zubiri concibe la materia como unidad de elementos en estado constructo, de modo que cada elemento tiene una determinada posición dentro del sistema" ${ }^{\prime 72}$. Consiste en la realidad física dinámica de la totalidad del cosmos. A esta materia se le atribuye "espaciosidad" y "temporalidad" en su sentido igualmente físico. En tercer lugar, aborda la cuestión de "El fundamento biológico de la historia"73. Detengámonos sobre el tema.

Como en Zubiri los seres materiales devienen seres vivientes cuando irrumpe la vida en el planeta Tierra. La materia físicocosmológica adviene "materia viva [a la que] le compete un singular dinamismo, el dinamismo de la vida biológica"74 -cayendo casi en una tautología-. No es como en K. Krause que "el mundo es un organismo vivo, penetrado de pensamiento y voluntad"75 -aunque se recoge el tema de la centralidad de la vida-, sino que se parte del hecho de que hay una irrupción de vida, primero, y posteriormente una evolución de la vida hasta alcanzar a la estructura que constituye el ser humano, que tiene "determinantes fundamentalmente biológicas" tanto onto- (en cada individuo) como filéticamente (en la especie humana). Aún "la primera función de la inteligencia [...] es biológica, esto quiere decir [como enseña la Etica de la Liberación] que es por exigencias biológicas por lo que ha aparecido este animal singular que llamamos hombre" ${ }^{\prime 77}$. A la humanidad, entonces, se ha llegado por evolución, por "evolución" de la vida en al Tierra. Y escribe, ahora corrigiendo su posición ortegeana anterior:

"En el seno de la nueva estructura morfológica florece un psiquismo que conserva transformadamente ${ }^{78}$ los momentos básicos del psiquismo de la especie anterior. La nueva especie tiene, por ejemplo, muchos instintos de la anterior ${ }^{1779}$.

De una manera más precisa indica todavía, y refiriéndose a la inteligencia, el problema con un texto de Zubiri:

"Esta función superior no sólo ha sido reclamada por la inferior, sino que está sustentada por ella, justo por aquello mismo que en esta función inferior (y para ella lo que es) exige la función superior; es lo que he solido llamar subtensión dinámica de unas funciones por otras" ${ }^{\prime \prime 0}$. 
La evolución de la vida se transmuta en proceso histórico: "La procesualidad de la historia es, por lo pronto, una procesualidad biológica, aunque, repitámoslo una vez más, no se reduzca ni a ser procesualidad ni a ser algo puramente81 biológico" ${ }^{\prime \prime 2}$.

Para Ellacuría la materialidad de la historia, entonces, supone la materia misma, el espacio, el tiempo y la vida "biológicamente considerada" $^{\prime \prime 3}$. La diferencia entre la mera evolución y la historia consiste en que esta última, aunque regida siempre por la necesidad y el azar, se mueve dentro de estos parámetros de manera propia. Es toda la cuestión de la libertad ${ }^{84}$-cuestión que nos alejaría de nuestro tema-.

De inmediato se toma otro atajo. Se trata de relacionar la historia, con transformación diversa de la evolución, con el trabajo humano como elemento creador. Aquí, evidentemente, se manifiesta un cierto déficit de lectura de K. Marx, al que se hace simpática referencia sin demasiada precisión -sobre los temas del valor de uso y de cambio, que hubieran sido una oportunidad de mostrar la relación entre la vida humana, sus necesidades, la utilidad del valor de uso y las relaciones sociales de intercambio para posibilitar la vida humana como phylum ${ }^{85}$. Nos dice:

\begin{abstract}
"Mientras que el puro ${ }^{86}$ hacer biológico del animal lo que logra es una acomodación de lo que es él al medio, en el hombre lo que más predomina es la acomodación del medio a su propia realidad [...] Así, aunque el motor primero del acto técnico, como de cualquier otro acto de la inteligencia, sea biológico -el de sobrevivir-, no por ello se reduce a ser puramente biológico ${ }^{\prime \prime 87}$.
\end{abstract}

El ser humano, entonces, íntegramente es una "realidad viva" ${ }^{\prime 8}, \mathrm{y}$ en tanto tal la historia es una "historia natural" ${ }^{\prime 89}$, en cuanto el punto de partida supone una "transmisión genética, esto es, un fenómeno plenamente natural"90. "La historia lleva consigo la naturaleza, como lleva consigo la evolución natural"91. Pero la vida humana, como la historia, no es sólo natural, es también social. Aquí, nuevamente, se advierte una cierta ambigüedad. Se toma a lo animal como lo exento de ninguna socialidad, sabiendo que los animales superiores, en el nivel de los mamíferos y especialmente los primates, hay ya atisbos se socialidad que la socialidad humana subsume.

De todas maneras:

"Esto va a hacer que la vida sea desde sus comienzos no una mera vivencia, sino una estricta convivencia. Como animal de realidades, el hombre se halla constitutivamente vertido a los demás por su propia estructura específica [...] Su vida es la actualización de esa versión real a los demás; su vida es así estricta convivencia"9 ${ }^{\prime \prime 2}$. 
Dejando muchos temas que no son los que pretendemos tratar en este corto trabajo -sobre la vida en el pensamiento de Ellacuría-, se vuelve sobre la cuestión muchas páginas adelante, proponiendo como un resumen:

"No hay una vida natural y una vida humana o existencia humana, sino que hay una sola vida humana y esta vida es siempre forzosamente natural. Ciertamente, entre la vida natural, tal como se da fuera del hombre, y la vida humana, tomada en su integridad, hay una profunda diferencia en tanto que vida93. Y la hay porque entre una y otra media un proceso, un proceso que Zubiri llamó desde sus primeros cursos un proceso de liberación"94. "Liberación significa que van a aparecer funciones nuevas, que aparecen desde las anteriores y en ellas, pero que son estrictamente nuevas ${ }^{\prime \prime 95}$.

Esto en el orden de la evolución. Pero la historia es algo distinto, porque "el tiempo humano ha de verse desde lo que es la vida humana integralmente considerada, esto es, como una única vida que abarca y supera lo natural"96, porque el ser humano puede crear como un libreto, "la unidad argumental de la vida" ${ }^{\prime 97}$, por el que, gracias a la memoria, el presente vital se une al pasado recordado y al proyecto futuro de la propia vida:

"Pero hay en la vida más que esto. El argumento de la vida no está compuesto únicamente por las acciones de la vida, consideradas como un continuo extensivo y disenso; está compuesto de manera principal por las opciones que va tomando el hombre"98. "En la medida en que soy autor opcional del argumento de mi vida, mi vida es vida y es mía [...] El hombre, en efecto, es agente y autor de su vida"199

Aquí hemos vuelto casi a Ortega y Gasset, pero por mediación de la metafísica zubiriana.

Lo no natural de la historia es el modo de transmitir de una generación a la otra los resultado de la estructura que se ha ido tramando de las opciones concretas de todos los seres humanos sobre las instituciones que se han ido creado. Ese totum, nos dice de nuevo ambiguamente Ellacuría, "no es una transmisión puramente biológica"100. No es una transmisión genética sino por medio de la tradición intersubjetiva. La memoria colectiva de cada comunidad, cada pueblo, de la humanidad, va pasando de generación a generación (no sólo genéticamente) las estructuras culturales logradas a través de los milenios por todo 
los actores sociales, y en las cuales todos los nuevos miembros son introducidos. Esa transmisión, no sólo genética, es una "transmisión tradente", una "entrega [que] se llama parádosis, traditio, tradición"101:

"Es este peculiar modo humano de ser introducido en la vida humana [como historia] para que en su momento esté en la realidad de una forma determinada lo que nos acerca a lo que es la realidad histórica"102. "El hombre, por tanto, además de recibir por transmisión genética determinadas estructuras psico-orgánicas, recibe también, aunque no genéticamente, determinadas formas de estar en la realidad"103. "La instalación en la vida humana es una instalación recibida, que presupone una transmisión genética, pero que responde formalmente a una entrega"104.

Ahora sí ha desaparecido toda ambigüedad. Además de lo expuesto se ocupa del "sujeto de la tradición", que en último término, y muy biológicamente, es el phylum, la especie humana al que hay que articular "la vida personal" -modo propio de la vida humana-. Páginas densas donde Ellacuría, siempre partiendo de la vida humana se hacer cargo de la impersonalidad de la historia articulándola con el argumento de la vida personal. Como, por otra parte, siempre se da el proceso como una "estructura dinámica de la historia", se pueden entender "los momentos estructurales de la historia" en su transformación. "Fuerzas históricas" que son "fuerzas biológicas", políticas, económicas, técnicas; es decir, "la praxis se identifica así con el proceso histórico mismo, en cuanto este proceso es productiva y transformativo"105.

Puede entonces observarse que I. Ellacuría aunque en su etapa definitiva tomará el tema de la "realidad" (tomado de Zubiri) como central (y que no ha sido para nada objetivo de este corto trabajo), sin embargo, la cuestión de la "vida" es el que atraviesa toda su vida intelectual, siendo el criterio mismo de acceso a la cosa real en cuanto a su realidad. Faltó quizá radicalizar la vida humana en cuanto al fundamento de las necesidades más perentorias como el comer, el beber, el vestirse, el tener habitación, el poner poseer autonomía cultural, lingüísti$\mathrm{ca}$, religiosa, las cuales son necesidades de la vida humana -incluyendo las experiencias místicas de $\mathrm{H}$. Bergson, como hemos visto-. Esto le hubiera dado mayor conciencia y fundamentado teóricamente mejor sus compromisos políticos concretos. Ciertamente lo hubiera hecho si su vida, su vida propia concreta, no hubiera sido tronchada por el acto irracional de una dictadura militar organizada desde el Departamento de Estado Norteamericano, que lo enalteció al nivel de los mártires de su pueblo salvadoreño, y uno de los héroes prototípicos de las nefastas 
décadas de tiranía en América Latina, que en el mejor de los casos juzgan y condenan a los Videlas, pero no pueden tocar a los Henry Kissinger, que fueron los cobardes estrategas de aquellas matanzas.

Como una última anécdota. Recuerdo que en 1972, en una conferencia que dicté en la Universidad Centroamericana en San Salvador, Ignacio (con el que hicimos una buena amistad) estaba en la primera fila de un numeroso público, junto al que sería uno de los dirigentes del Frente Farabundo Martí de Liberación Nacional, exponía los principios de la reciente Filosofía de la Liberación que habíamos originado en el sur del continente, $y$, conversando posteriormente con él, claramente asintió -como acontecería el año siguiente en Buenos Aires con Augusto Salazar Bondy- en su posibilidad e importancia. No es extraño que años después escribiera un artículo sobre "Función liberadora de la filosofía"106, donde leemos:

"Puede decirse que la filosofía desde siempre, aunque de diversas formas, ha tenido que ver con la libertad. Se ha supuesto que es tarea de hombres libres en pueblos libres, al menos de aquellas necesidades básicas que impiden ese modo de pensar que es la filosofía; se ha admitido también que ha ejercido una función libertadora para quien filosofa y que, como ejercicio supremo de la razón, ha liberado del oscurantismo, de la ignorancia, y de la falsedad a los pueblos"107.

Valgan estas reflexiones como continuación de un diálogo necesario para la fundamentación material y formal de la ética, ya que ambas son hoy más obligatorias que hace unos años por la corrupción global creciente, guardando sus niveles correspondientes y articulando ambos temas (lo material y lo formal) sin última instancia, por el momento.

\section{Bibliografía citada}

- Bergson, Henri, 1932, Les deux sources de la morale et de la religión, PUF, Paris.

- Damasio, Antonio, 1994, Descartes' Error. Emotion, Reason, and the Human Brain, A. Grosset, New York.
- Damasio, A., 2003, Looking for Spinoza. Joy, Sorrow, ant the Feeling Brain, Harcourt, New York.

- Dussel, Enrique, 1969, El humanismo semita, Eudeba, Buenos Aires. 
- Dussel, E., 1974, Método para una filosofía de la liberación, Sígueme, Salamanca.

- Dussel, E., 1975, El humanismo helénico, Eudeba, Buenos Aires.

- Dussel, Enrique, 1977, Filosofía de la Liberación, Edicol, México.

- Dussel, E., 1998, Etica de la liberación, Trotta, Madrid.

- Dussel, E., 1999, "Sensibility and Otherness in Emmanuel Lévinas", en: Philosophy Today (Chicago), Vol. 43: 2, pp. 126-134.

- Dussel, Enrique, 2001, "Algunas reflexiones sobre la falacia naturalista", en Diánoia (UNAM, México), XLVI, 46, pp. 65-79.

- Dussel, E., 2004, "Sobre algunas críticas a la Etica de la Liberación. Respuesta a Julio Cabrera", en Diánoia, XLIX, 52, pp.125-143.

- Ellacuría, Ignacio, 1991, Filosofía de la realidad histórica, Trotta, Madrid.

- Ellacuría, I., 1996, Escritos filosóficos, UCA Editores, San Salvador, vol. 1-3 (2001).

- Ellacuría, I., 1996b, Escritos políticos I, UCA, San Salvador

- Flores García, Víctor, 1997, El lugar que da verdad. La filosofía de la realidad histórica de Ignacio Ellacuría, Universidad Iberoamericana, Porrúa, México.

- Gutiérrez, Germán, 2006, "Sobre Damasio y el principio material universal", en Revista de filosofía latinoamericana (Maracaibo), (2005), pp. - ..

- Hegel, 1970, Hegel. Werke in zwanzig Bänden. Theorie Werkausgabe, Suhrkamp, Frankfurt. Traducción de la Lógica por Rodolfo Mondolfo, 1968, La ciencia de la lógica, Hachette, Buenos Aires.

- Marx, Karl, 1956, Marx-Engels Werke (= MEW), Dietz Verlag, Berlin, en decenas de volúmenes.

- Miranda, José Porfirio, 1989, Hegel tenía razón. El mito de la ciencia empírica, UAM-Iztapalapa, México.

- Miranda, J. P., 2006, "El bien y las ciencias sociales", inédito.

- Ramírez, Santiago, 1958, La filosofía de Ortega y Gasset, Barcelona.

- Rojas, Mario, 2002, Der Begriff des Logischen und die Notwendigkeit universell-substantieller Vernunft, Concordia, Aachen.

- Rojas, M., 2005, "Vida humana, razón humana, razón objetiva. Crítica racional de la crítica de Dussel a la razón", en Andamios (UACM, México) 2005, II, 3, pp. 79-105.

- Rojas, M., 2006., "Filosofía crítica y defensa de la vida humana. Reflexiones críticas en torno a la Etica de la Liberación de E. Dussel", inédito. 
- Rojas, M., 2006b, "III. Fundamentación última de la ética y razón ético-objetiva", inédito.

- Zubiri, Xavier, 1981, Inteligencia sentiente, Alianza Editorial, Madrid.

Notas

1 Véase Dussel, 2004.

2 ECA, (1979), 368, pp. 418-428 (Ellacuría, 1996, vol. 3, pp. 251-270). Nos dice: "La razón última por la cual lo biológico debe intervenir en la fundamentación de la ética estriba en que los biológico es momento constitutivo de la realidad humana" (1996, p. 252).

3 Dussel, 1998, p. 141.

4 Dussel, 1974, p.16.

5 Miranda, 2006, p.7.

6 "El significado mismo de real es el espíritu percibido en autoconciencia" (2006, p. 8). "El nirvana ya entendió que la realidad consiste en los actos del espíritu" (Ibid.).

Rojas, 2005, p.103.

8 Rojas, 2002, p.228ss. "Er begreift sich als reine Selbstreflexivität, reine Subjektivität, logisch-kategoriales Selbstbestimmen; sein notwendiger Inhalt sind alle die oben entwickelten Bestimmtheiten" (p. 245).

$9 \quad$ Zubiri, 1981, p. 77-78.

$10 \quad$ Ibid., p. 191.

11 Ibid., pp.211-212.

$12 \quad$ Ibid ., p. 233.

13 Miranda, 1989.

- Zubiri, X., 1992, Sobre el sentimiento y la volición, Alianza Editorial, Madrid.

- Zubiri, X., 1995, Estructura dinámica de la realidad, Alianza Editorial, Madrid.

77
mi obra Dussel, 1998. F. Hinkelammert escribe: "Los juicios de hecho cuyo criterio de verdad es la vida y muerte, son a la vez los juicios constituyentes de la realidad objetiva [...] La realidad objetiva no es lago dado independientemente de la vida del hombre. Es la vida del hombre, al lograr evitar la muerte, que mantiene la realidad como realidad objetiva. Por eso en el suicidio se disuelve la realidad, y en el suicidio colectivo de la humanidad la realidad se disuelve definitivamente [...] La objetividad de la realidad no 
antecede a la vida humana, sino es tanto su producto como su presupuesto" (Hinkelammert, 1996, p. 32). "Donde no hay necesidades, tampoco hay mundo objetivo. La objetividad de la realidad existe solamente desde el punto de vista del sujeto natural y necesitado" (Ibid.).

21 Recordando con Zubiri y con Heidegger, y aún más con el mismo Marx, que el valor es la posición de una mediación o posibilidad con respecto a su fin; dicho fin es en último caso la plena realización de la vida humana en cuanto tal. Por ello la vida humana tiene dignidad y funda todo valor. Para Marx, en la economía política, el trabajo vivo, por ser la "fuente creadora del valor de cambio", no tiene valor (el salario "no paga el valor del trabajo") sino dignidad. El creer que el trabajo vivo tiene valor y que lo paga el salario es para Marx el carácter fetichista del mismo trabajo a los ojos aún del propio trabajador.

"Responsabilidad" como el "responder" por un huérfano como tutor ante un tribunal que lo acusa significa en latín: "tomar-a-cargo" aquello de lo que son "responsable". Lo que se toma a cargo no es sólo ni primeramente la vida propia, sino la vida del Otro, de los otros miembros de la comunidad (en último término de la humanidad entera).

En Escritos filosóficos, 1996, vol. 1, pp. 24-25 (cita de Ortega en Goethe desde dentro, en sus Obras completas, Madrid, 1947, vol. 4, p. 400).

26 Ellacuría, 1966, I, p. 28.
El artículo tiene por título: "Posibilidad y modo de aproximación entre la filosofía escolástica y la filosofía vitalista moderna (Reflexiones ante el libro de Ramírez La filosofía de Ortega y Gasset)". Yo estaba en esos momentos en España con motivo de mi doctorado en filosofía, y pude observar esa polémica. Ramírez, un anciano dominico conservador, pretendía con una lógica bien obvia y simplista destruir el pensamiento de Ortega al cual le aplicaba categorías escolástica sin comprender la existenciales que usaba Ortega a partir de Husserl y Heidegger (que Ramírez ignoraba en forma y contenido).

33 Cita de Ellacuría de Ortega, Historia como sistema, cit. por S. Ramírez, 1958, p.72).

34 Ellacuría, 1996, I, pp. 241-242.

35 Ibid., pp. 244ss.

36 Este "mundo" supondría la categoría heideggeriana, ignorada por Ramírez, a la que extrañamente Ellacuría de agrege aquí lo de "lo oprime": ¿presagios futuros de una filosofía de la liberación? 
con toda naturalidad. Es decir, el descubrimiento de Zubiri por parte de Ellacuría viene antecedido, como para el mismo Zubiri, del pensamiento de Ortega y Gasset, evidentemente. punto. Ellacuría indica: "En el hombre, efectivamente, sus necesidades biológicas se le presentan como algo venido de afuera [sic] 'a su auténtico [sic] ser, con que éste no tiene más remedio que contar [sic], pero que no lo constituye' (Op. cit., p.323). El animal tiene necesidades objetivas [sic] en cuanto que, por un lado, sin ellas, sin su objetiva satisfacción, no puede 
seguir viviendo [...] En el hombre [...] esas necesidades que llamamos objetivas $[\ldots]$ son realmente necesidades que hay que sufrir: algo que no es lo suyo y con lo que, sin embargo, hay que contar, no hay más remedio [sic] que aceptar, si es que quiere vivir" (Ellacuría, ibid., p.442). Nos pareciera escuchar el lamento del "alma" que se entristece por el hecho de tener un "cuerpo" con sus necesidades animales. No se exalta la alegría del "comer humanamente" -que es inescapable para el ser humano, porque sólo y siempre come humanamente- en comunidad festiva (y rebelarse por ello contra el "hambre" del pobre que sufre la injusticia: su hambre nunca es animal tampoco), sino más bien expresa la tristeza de un mundo donde se pudiera vivir sin perder el tiempo en comer, que algunos místicos maniqueos manifestaban frecuentemente. Es Ortega todavía, y el joven filósofo se está sólo educándose en el dolor (no el "frío", porque más bien es el "calor" lo insoportable) de la pobreza y el hambre centroamericanos.

Como puede verse hay todavía una completa separación entre las necesidades "humanas" (espirituales, culturales, etc.) y las puramente animales (comer, beber, protegerse del frío o calor, tener una protección durante las peligrosas horas de la noche, etc.). La exigencia ética: "Di pan al hambriento, de beber al sediento..." del Libro de los Muertos de Egipto, capítulo 125, no cumplen necesidades animales o biológicas, cumplen exigencias humanas y por ello son imperativos éticos universales. El vitalismo de Ortega no es suficiente, y es tan dualista, o casi, como el de Porfirio

Miranda. Evidentemente K. Marx se sitúa desde sus Manuscritos del 44 hasta su muerte, en un a comprensión unitaria de la vida como la que propone X. Zubiri o la Etica de la Liberación contra Ortega y Gasset, aunque parezcan muy similares. otra parte, la visión "metafísica" de la biología o vida humana en Ellacuría no le hace dar mayor importancia al hecho de las "necesidades" de la vida humana y a su negatividad: la necesidad del comer, por ejemplo, y la negatividad del hambre, como corolario del hecho metafísico del modo viviente de la realidad humana. Esto lo hubiera situada más cerca de Marx, de Hinkelammert y de la Ética de la Liberación explícitamente en su materialidad viviente. 


\begin{tabular}{|c|c|c|c|}
\hline 75 & $\begin{array}{l}\text { Ellacuría, 1991, p. } 78 \text {. En América } \\
\text { Latina Krause tuvo muchos segui- } \\
\text { dores en el siglo XIX. Cita Ella- } \\
\text { curía la obra fundamental de éste } \\
\text { Grundwahrheiten der Wissenschaft, } \\
\text { zugleich in ihrer Beziehung zu dem } \\
\text { Leben (Gotinga, 1829, pp. 561-586). } \\
\text { No se trata de un vitalismo cosmo- } \\
\text { lógico. }\end{array}$ & 85 & $\begin{array}{l}\text { de la "acción humana" desde el } \\
\text { horizonte de la libertad, contra el } \\
\text { positivismo del comienzo del siglo } \\
\text { XX. En este sentido el mismo Ella- } \\
\text { curía lucharía contra un positivismo } \\
\text { materialista ingenuo al final del } \\
\text { siglo. } \\
\text { Ibid., pp. 118-136. }\end{array}$ \\
\hline 76 & Ibid., p. 79. & 86 & $\begin{array}{l}\text { De nuevo se deja ver una cierta am- } \\
\text { bigüedad. Al hablar de "puro" hacer }\end{array}$ \\
\hline 77 & $\begin{array}{l}\text { Ibid.. Obsérvese que no se habla } \\
\text { de una "vida animal", sino de un } \\
\text { "animal llamado hombre", es decir } \\
\text { la "animalidad" ha sido subsumida } \\
\text { en la "humanidad". }\end{array}$ & & $\begin{array}{l}\text { biológico no se entiende bien, por- } \\
\text { que todas las actividades humanas, } \\
\text { aún las superiores como el inteligir } \\
\text { o querer, no dejan de ser referidas a } \\
\text { la vida: son actividades biológicas }\end{array}$ \\
\hline 78 & $\begin{array}{l}\text { "Conservar transformadamente" re- } \\
\text { corta exactamente nuestra categoría } \\
\text { de "subsunción". }\end{array}$ & & $\begin{array}{l}\text { superiores. Pareciera (aunque es } \\
\text { contrario al pensamiento de Ellacu- } \\
\text { ría) que en el ser humano hubieran } \\
\text { actividades superiores que dejan de }\end{array}$ \\
\hline 79 & $\begin{array}{l}\text { Citando a Zubiri en "El origen del } \\
\text { hombre", en Ellacuría, ibid., p. } 85\end{array}$ & & $\begin{array}{l}\text { ser biológicas. Si es verdad que el } \\
\text { ser humano puede transformar la }\end{array}$ \\
\hline 80 & $\begin{array}{l}\text { Cit. de Sobre la esencia, pp. } 364-365 \\
\text { (Ellacuría, p.97). Esta "subtensión } \\
\text { dinámica" es nueva y exactamente } \\
\text { la "subsunción" de la que habla- }\end{array}$ & & $\begin{array}{l}\text { realidad en vista de su proyecto de } \\
\text { nueva realidad, no deja de ser bioló- } \\
\text { gico todo ello, pero biológicamente } \\
\text { humano. }\end{array}$ \\
\hline & mos. & 87 & Ibid., p. 133. \\
\hline \multirow[t]{7}{*}{81} & En este "puramente" renace una & 88 & Ibid., 134. \\
\hline & $\begin{array}{l}\text { ambigüedad todavía. El proceso } \\
\text { histórico es de la vida humana, por }\end{array}$ & 89 & Ibid ., pp. 136 ss. \\
\hline & lo tanto biológicamente humano, y & 90 & Ibid., p. 137. \\
\hline & no algo más que puramene bioló- & 91 & Ibid., p. 139. \\
\hline & biológico, pero biológicamente & 92 & Ibid., p. 175. \\
\hline & $\begin{array}{l}\text { humano. Lo biológico cuando es } \\
\text { humano es siempre y sólo lo "bio- }\end{array}$ & 93 & $\begin{array}{l}\text { Ahora ha desaparecido toda ambi- } \\
\text { güedad. }\end{array}$ \\
\hline & lógicamente & \multirow[t]{3}{*}{94} & Ibid., p. 325. Esta expresión indica \\
\hline 82 & Ellacuría, 1991, p. 103. & & la vida se va "liberando" de sus \\
\hline 83 & Ibid., p.104. & & $\begin{array}{l}\text { ataduras inferiores y posibilitando } \\
\text { actuaciones superiores. No se usa }\end{array}$ \\
\hline \multirow[t]{4}{*}{84} & \multirow{4}{*}{$\begin{array}{l}\text { Cabe aquí igualmente recordar que } \\
\text { Ellacuría se encarga de exponer } \\
\text { algunos aspectos de la posición de } \\
\text { Blondel en un artículo de juventud } \\
\text { (Ellacuría, 1996, I, pp.545 ss), que } \\
\text { expone exactamente el problema }\end{array}$} & & $\begin{array}{l}\text { la expresión en el sentido de una } \\
\text { filosofía de la "liberación". }\end{array}$ \\
\hline & & 95 & Ibib., p. 326. \\
\hline & & 96 & Ibid., p. 331. \\
\hline & & 97 & Ibid., p. 375. \\
\hline
\end{tabular}


mosquito, pero tan biológica como

99 Ibid., p. 376. "Es ésta una [...] dimensión de la vida humana, aquella por la cual el hombre es actor en su vida del papel que la historia le ha forzado a representar. El hombre actúa y a veces lo hace opcionalmente, pero lo hace dentro de una trama transindividual en una conexión de situaciones" (Ibid., p. 377). Se trata de un "agente-autoractor".

Ibid., p. 388. Esa transmisión, aclaro yo, es "biológicamente humana", y no "no puramente biológica". Pareciera que las funciones superiores del cerebro (como conciencia, autoconciencia, intelección, volición, etc.), no son biológicas. Si son cerebrales son biológicas, pero son de un cerebro humano, no de un las del mosquito -aunque con diferencia de grado, esencial, en sentido zubiriano-.

101 Ibid., p. 390 (cit. de Zubiri).

102 Ibid..

103 Ibid..

104 Ibid., p. 391.

105 Ibid., p. 472.

106 ECA (San Salvador) (1985) 435-436, pp. $45-64$.

107 Ibid., p. 45. Pareciera estar corrigiendo la definición de Kant sobre la Aufklaerung. Porque en vez de "liberar de la inmadurez autoculpable” a los que temen la razón eurocéntrica, se habla ahora de liberar "a los pueblos", simplemente. 